\title{
Rationale construction of individual elements of technological complex
}

\author{
Kirill Nemtinov ${ }^{1,}{ }^{*}$, Alexsey Eruslanov ${ }^{1}$, and Yulia Nemtinova $^{1,2}$ \\ ${ }^{1}$ Tambov State Technical University, 392000, Sovetskaya st., 106, Tambov, Russia \\ ${ }^{2}$ Tambov State University named after G.R. Derzhavin, 392000, Internatsionalnaya st., 33, Tambov, \\ Russia
}

\begin{abstract}
In this paper, we propose the substantiation procedure of a technological complex design on the example of a seeding complex. As a result of performed research, design of the seeding complex for grain crops has been improved using non-standard devices and typical parts that provide: reduction in the time of seeding and energy consumption, possibility of using the seeding complex as a cultivator and a disk harrow. Analysis of computational research results allowed us to specify the following parameters: disc angle of 15 degrees, while the specific traction resistance of the seeding complex does not exceed $3.44 \mathrm{kN} / \mathrm{m}$ on the stubble background, and $3.19 \mathrm{kN} / \mathrm{m}$ on the fallow background. Field studies of the developed complex has shown that at the given seeding depth (with the variation $\pm 1 \mathrm{~cm}$ ) the accuracy is $83.5 \ldots 84.2 \%$. Optimum quantity of plants of grain crops per unit area is provided under the following conditions: bucket volume $7,2 \mathrm{dm}^{3}$, distance between buckets $0.21 \mathrm{~m}$; speed of the bucket elevator is $0.12 \mathrm{~m} / \mathrm{s}$. The proposed design of the seeding complex is recommended to be used for combining several operations: soil preparation, sowing of cereals and soil packing.
\end{abstract}

\section{Introduction}

In modern conditions much attention is paid to the issues of strengthening the agricultural complex in the Russian Federation. The Government of the country has taken a number of serious systemic measures and developed general proposals on certain elements of state regulation in the agro-industrial complex, which are designed to significantly improve the situation in the industry and efficiency of food program implementation. Solution of the problems to be solved by the industry can't be found without new types of agricultural machinery, effective fertilizers, and improved storage conditions of agricultural products.

The use of computer technology and advanced software to a large extent allows solving most of these problems with maximum efficiency.

Development of modern agricultural machinery is mostly performed at the stage of design, where the technical level of machines, their main characteristics and design solutions are defined. The shortcomings, which might arise at this stage, are difficult and often impossible to be altered at subsequent stages of their life cycle. At present, technical

\footnotetext{
*Corresponding author: nemtinov@mail.gaps.tstu.ru
} 
systems are being applied at design stages of technological complexes in the agricultural sector.

Analysis of literature sources describing technologies of computer-aided design of agricultural machinery [ 1 - 7] has shown that they focus primarily on design of individual agricultural complexes or their nodes, and to a lesser extent on selection of the optimal one from the standpoint of different criteria, namely, its structural scheme tied to specific input data defined by technical specification and consumers: types of seeds, soil types and moisture, technology of its processing, traction class of the tractor, etc. [8 - 13].

In connection with this, we have proposed to improve design features of the seeding complex (SC) for grain crops and to develop its original design, including a seed drill and a disc harrow.

\section{Improvements in the design of technological complexes}

For engineering development of a technological complex on the example of a SC, it is necessary to achieve the following advantages in comparison with analogues:

- reduction of sowing works duration as there is no gap between soil preparation and sowing;

- reducion of energy consumption by combining the operations of soil preparation, processing, sowing and packing of soil in one device (the use of diesel fuel for the whole cycle of sowing works is no more than $41 /$ ha compared to the cost of performing these operations separately $\sim 5-71 /$ ha);

- optimal depth of sowin at the level of dew point, preserving the initial states of the capillaries, which ensure the natural supply of moisture from the ground;

- use of up to $40 \%$ of typical domesticly produced units and mechanisms;

- the possibility of using the SC as a cultivator and a disk harrow.

The problem of automated formation of acceptable structural diagrams of a SC in accordance with the project specifications and finding the optimal one taking into account many criteria is rarely solved. This is due to various difficulties, including those that arise during formalization of the task. To solve such problems, expert systems are most often used. Figure 1 shows the main nodes of sowing complexes.

Based on system analysis methods, an improved design of the seeding complex, which includes soil preparation, processing, sowing and soil packing operations in one device, contains the following main organs, devices and mechanisms: frame = "solid", grain tank = "general", packing device = "pneumatic tires", sowing unit = "disk knives", metering device = "coil type", transporting mechanism = "bucket elevator".

Next, electronic models of devices and mechanisms of the SC were developed and its prototype was created on their basis. Visualization of the electronic geometric model of the whole SC is shown in Fig. 2.

\section{Analysis of computational and field experiments}

To substantiate the designs of individual elements of the SC, computational and field studies were carried out.

Field tests of the experimental SC has shown high efficiency of the proposed design solution, providing a cost reduction of up to $15 \%$ and an increase in operating efficiency of $17 \%$ compared to the analogues. 


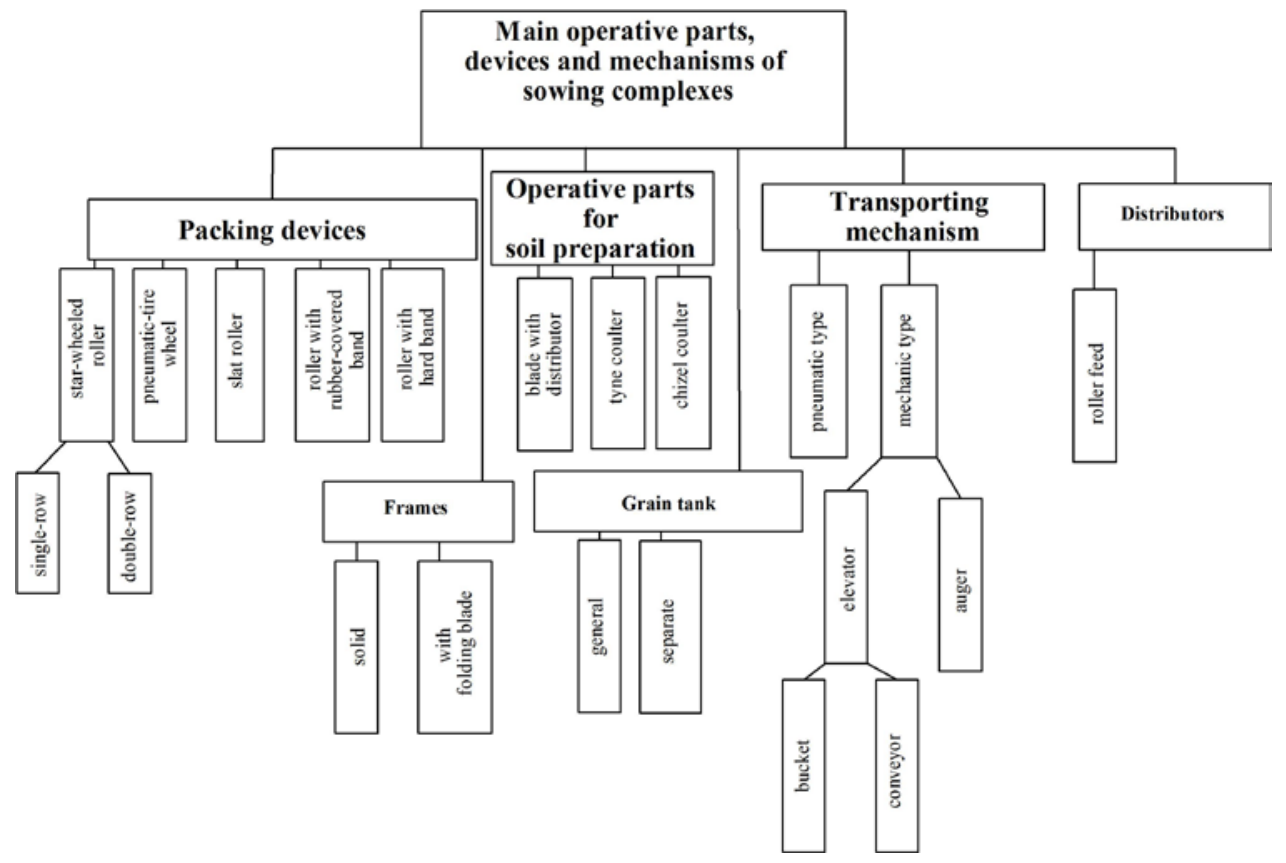

Fig. 1. Structure diagram of the main operative parts, devices and mechanisms of sowing complexes

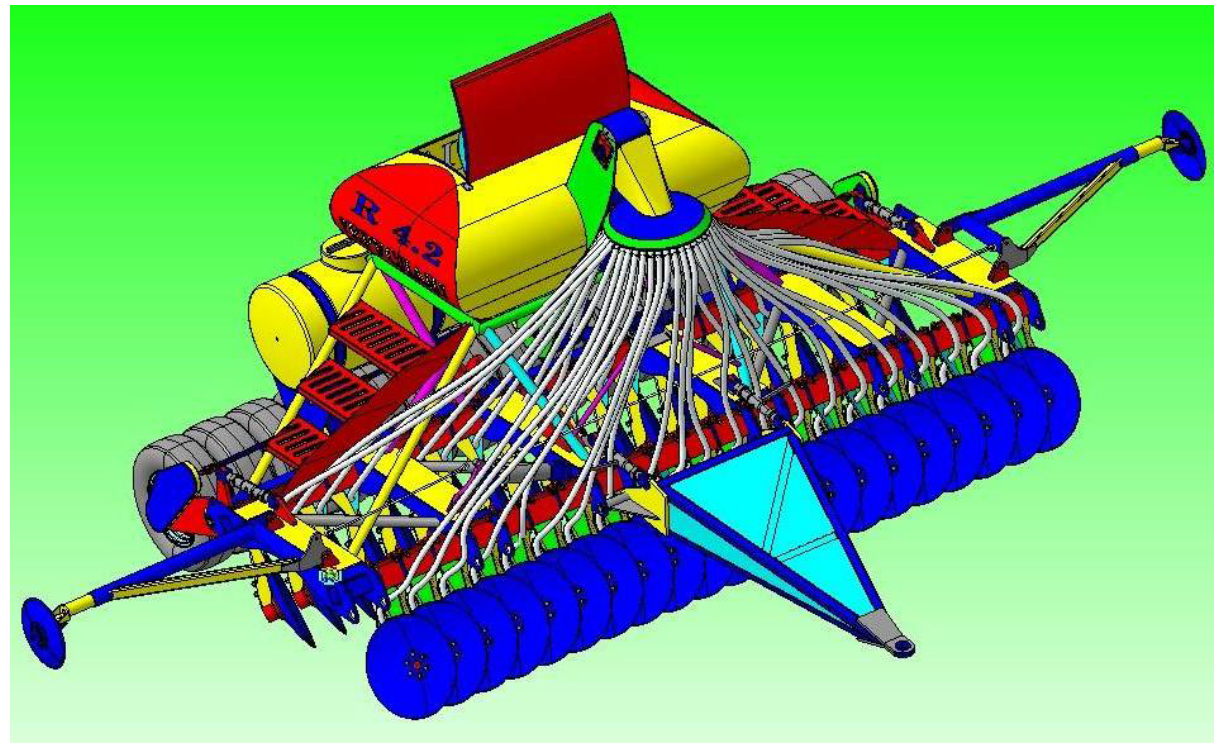

Fig. 2. Visualization of an electronic geometric model of a SC

Determination of energy parameters of the sowing process carried out with the developed SC was performed using IP-264 measuring information system intended for research and testing purposes, as well as power, operational and technological evaluations of machines and traction tests of tractors. 
Based on design features of the developed SC, refinement of the most optimal values of its design parameters was carried out for a disk knife. In the course of experimental studies, the angle of inclination of the disk varied in the range from 10 degrees to 20 degrees.

As a result of experimental analysis, data shown in Fig. 3 was obtained and correlation between the value of specific traction resistance $\mathrm{R}\left(R_{\mathrm{Cc}}\right.$ - on the stubble background, $R_{\mathrm{Cn}}$ on the fallow background) and the studied parameter was determined as a second degree polynomial.

As a result of experimental data approximation by the least squares method the correlation between the slope of the disk $l_{\Gamma}$ and specific traction resistance of the developed SC was obtained (see Fig. 3).

The extreme (minimum) values of these functions are achieved at a disc angle of 15 degrees, while specific traction resistance of the SC on the stubble background does not exceed $3.44 \mathrm{kN} / \mathrm{m}$, and on the fallow background does not exceed $3.19 \mathrm{kN} / \mathrm{m}$. This angle of inclination was accepted for the final version of the SC.

The optimal number of plants of grain crops per unit area of planting is largely related to the functioning of the bucket elevator and is provided by varying the following parameters: bucket capacity, distance between the buckets and speed of the bucket elevator.

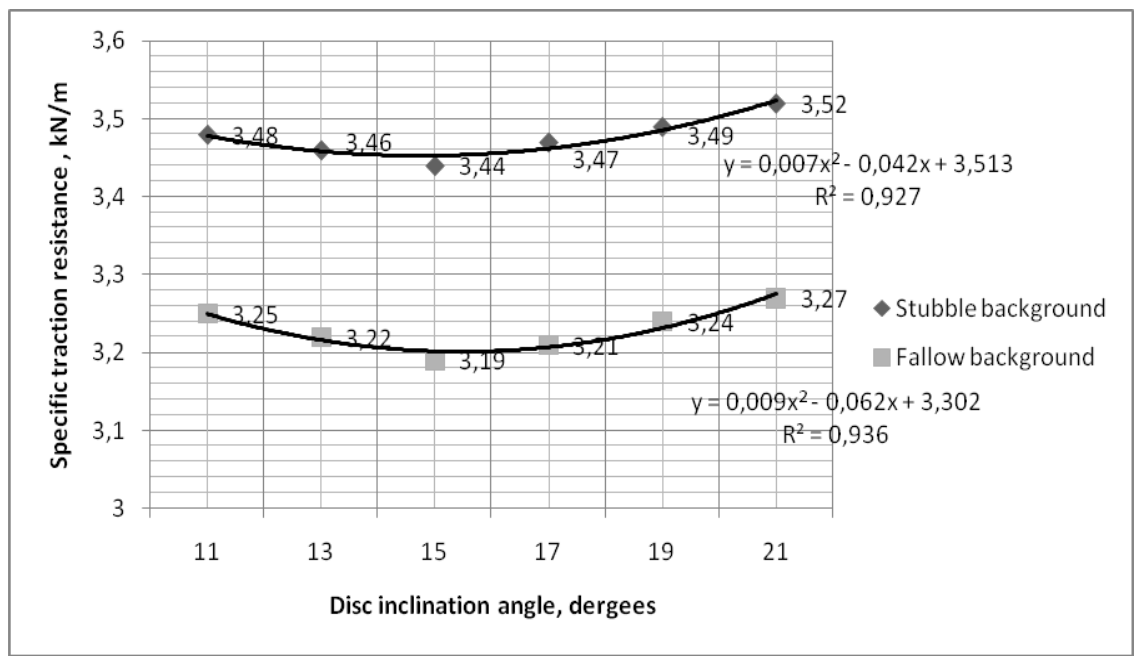

Fig. 3. Correlation between specific traction resistance and disk inclination angle

The optimal values of these parameters were determined as a result of a computational experiment using the orthogonal central composition plan of the experiment. The bucket capacity $\left(x_{1}\right)$ varied in the range from $3.0 \mathrm{dm}^{3}$ to $9.5 \mathrm{dm}^{3}$; the distance between the buckets $\left(x_{2}\right)$ was in the range from $0.1 \mathrm{~m}$ to $0.25 \mathrm{~m}$; and the speed of the elevator $\left(x_{3}\right)$ - in the range from $0.047 \mathrm{~m} / \mathrm{s}$ to $0.16 \mathrm{~m} / \mathrm{s}$. Figure 4 shows a kinematic scheme of a bucket elevator.

As a response function, we used the function:

$$
f\left(x_{1}, x_{2}, x_{3}\right)=\left|N_{v}-N_{\text {экс }, i}\right|,
$$

where: $N_{v}$ - seeding rate per $1 \mathrm{~m}^{2}, N_{\text {экс, } i}$ - number of seeds during the $i$-th experiment, $i=1$, $2, \ldots, 15$.

Variation levels of selected factors are given in Table 1. For three factors, correction of their squares $a=0.73$, "star shoulder" $\alpha=1.215$. Experimental results are given in Table 2 .

Optimal quantity of plants of grain crops per unit area of sowing is provided with the following parameters: bucket volume $-7,2 \mathrm{dm}^{3}$, distance between the buckets $-0.21 \mathrm{~m}$; the 
speed of the bucket elevator $-0.12 \mathrm{~m} / \mathrm{s}$. As the degree of polynomial increases, their values remain unchanged.

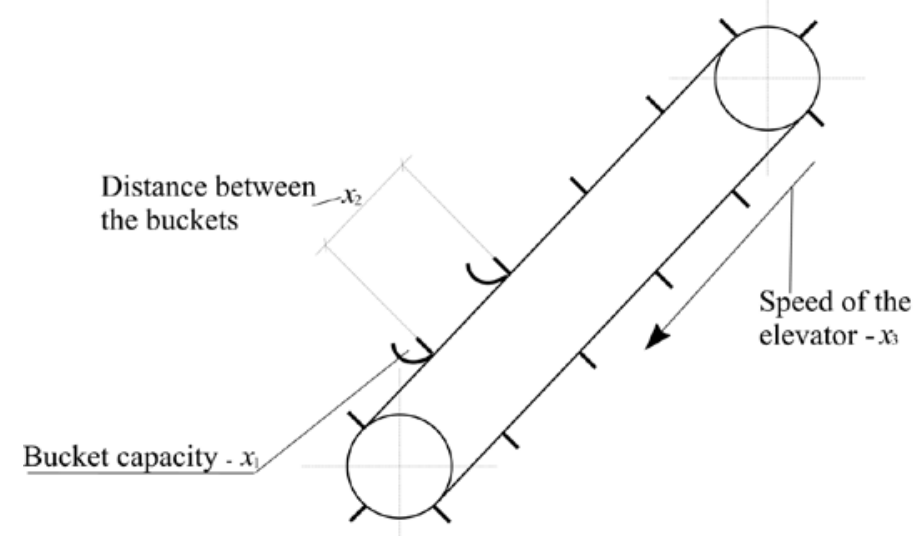

Fig. 4. Kinematic scheme of a bucket elevator

Table 1. Variation levels of selected factors

\begin{tabular}{|c|c|c|c|c|c|}
\hline Factor & $-\alpha$ & -1 & 0 & +1 & $+\alpha$ \\
\hline$x_{1}$ & 3.0 & 3.48 & 6.25 & 8.83 & 9.5 \\
\hline$x_{2}$ & 0.1 & 0.11 & 0.175 & 0.236 & 0.25 \\
\hline$x_{3}$ & 0.047 & 0.057 & 0.104 & 0.15 & 0.16 \\
\hline
\end{tabular}

Table 2. Experimental results

\begin{tabular}{|c|c|c|c|}
\hline $\begin{array}{c}\text { Level of } \\
\text { factor } x_{1}\end{array}$ & $\begin{array}{c}\text { Level of } \\
\text { factor } x_{2}\end{array}$ & $\begin{array}{c}\text { Level of } \\
\text { factor } x_{3}\end{array}$ & $\begin{array}{c}\mid N_{v}- \\
N_{\text {экс, },} \mid\end{array}$ \\
\hline-1 & -1 & -1 & 152 \\
\hline 1 & -1 & -1 & 141 \\
\hline-1 & 1 & -1 & 145 \\
\hline 1 & 1 & -1 & 96 \\
\hline-1 & -1 & 1 & 76 \\
\hline 1 & -1 & 1 & 56 \\
\hline-1 & 1 & 1 & 24 \\
\hline 1 & 1 & 1 & 15 \\
\hline$-\alpha$ & 0 & 0 & 56 \\
\hline$\alpha$ & 0 & 0 & 89 \\
\hline 0 & $-\alpha$ & 0 & 66 \\
\hline 0 & $\alpha$ & 0 & 97 \\
\hline 0 & 0 & $-\alpha$ & 98 \\
\hline 0 & 0 & $\alpha$ & 102 \\
\hline 0 & 0 & 0 & 29 \\
\hline
\end{tabular}

\section{Results and discussion}

As a result of performed research, design of the SC for grain crops has been improved using non-standard devices and typical parts that provide: reduction in the time of seeding and energy consumption, possibility of using the SC as a cultivator and a disk harrow. Analysis 
of computational research results allowed us to specify the following parameters: disc angle of 15 degrees, while the specific traction resistance of the SC does not exceed 3.44 $\mathrm{kN} / \mathrm{m}$ on the stubble background, and $3.19 \mathrm{kN} / \mathrm{m}$ on the fallow background. Field studies of the developed complex has shown that at the given seeding depth (with the variation \pm $1 \mathrm{~cm}$ ) the accuracy is $83.5 \ldots 84.2 \%$. Optimum quantity of plants of grain crops per unit area is provided under the following conditions: bucket volume $7,2 \mathrm{dm}^{3}$, distance between buckets $0.21 \mathrm{~m}$; speed of the bucket elevator is $0.12 \mathrm{~m} / \mathrm{s}$.

\section{References}

1. V.A. Nemtinov, Yu.V. Nemtinova. Journal of Computer and Systems Sciences International. 44(3), 389-398 (2005)

2. V.G. Mokrozub, V.A. Nemtinov A.V. Mokrozub. Chemical and Petroleum Engineering. 53(5-6), 326-331 (2017)

3. L. Lijing. Transactions of the Chinese Society of Agricultural Engineering. 31(11), 4045 (2015)

4. V.G. Mokrozub, V.A. Nemtinov. Chemical and petroleum engineering, 51(7-8), 31-35 (2015)

5. G.V. Prasanna Kumar, B. Srivastava, D.S. Nagesh. Computers and Electronics in Agriculture. 65(1), 26-35 (2009)

6. J.M. Wang, L. Zhang, Y.B. Liu, X.N. Mo, G.Q. Ren. Computer Integrated Manufacturing Systems. 16(10), 2017-2023 (2010)

7. V.G. Mokrozub, K.D. Manuilov, V.V. Gorshkov, T. S. Gorshkova. Chemical and Petroleum Engineering. 51(9-10), 613- 617 (2016)

8. A.B. Borisenko, S.V Karpushkin. Journal of Computer and Systems Sciences International. 53(3), 410-419 (2014)

9. A. Ivannikov, V. Kulagin, A. Romanov, B. Pozdneev. EWDTS-2016 Proceedings, 14th IEEE EAST-WEST DESIGN \& TEST SYMPOSIUM (2016)

10. E.N. Malygin, V.G. Mokrozub, V.A. Nemtinov. MATEC Web of Conferences 129 ICMTMTE (2017)

11. V. Vamerali, M. Bertocco, L. Sartori. Soil \& Tillage Research, 89(2), 196-209 (2006)

12. L. Yang, X.T. He, T. Cui, D.X. Zhang, S. Shi, R. Zhang. International Journal of Agricultural and Biological Engineering, 4, 1-9 (2015)

13. T. Zhao, Y. Zhao, T. Higashi, M. Komatsuzaki. Engineering in Agriculture, Environment and Food. 5(2), 50-56 (2012) 